\title{
Isaac syndrome
}

INSERM

\section{Source}

INSERM. (1999). Orphanet: an online rare disease and orphan drug data base. Isaac syndrome. ORPHA:84142

Isaac's syndrome is an immune-mediated peripheral motor neuron disorder characterized by continuous muscle fiber activity at rest resulting in muscle stiffness, cramps, myokymia, and pseudomyotonia. 